\title{
Comparative evaluation under routine conditions of the nitrate reduction assay, the proportion assay and the MGIT 960 assay for drug susceptibility testing of clinical isolates of Mycobacterium tuberculosis
}

\author{
Leila de Souza Fonseca/ ${ }^{+}$, Gisele Betzler de Oliveira Vieira, \\ Luciana Fonseca Sobral, Elizabete Oliveira Ribeiro, Anna Grazia Marsico
}

Laboratório de Micobacteriologia, Complexo Hospitalar Instituto de Doenças do Tórax/Hospital Universitário Clementino Fraga Filho, Universidade Federal do Rio de Janeiro, Rio de Janeiro, RJ, Brasil

The performance of the nitrate reductase assay (NRA) was compared with the proportion method (PM) on Lowenstein-Jensen medium and the BACTEC MGIT960 assay under routine conditions using 160 clinical isolates of Mycobacterium tuberculosis with a high proportion of resistant strains. The mean time to obtain results was 8.8 days and the overall agreements between NRA and PM and NRA and M960 were 95\% and 94\%, respectively. NRA was easy to perform and represents a useful tool for the rapid screening of drug-resistant $\mathrm{M}$. tuberculosis strains in low-resource countries.

Key words: tuberculosis - nitrate reductase assay - drug susceptibility

Tuberculosis (TB) remains a serious infectious disease with a worldwide distribution that results in high morbidity and mortality, mainly in countries with a low socio-economic status. Despite the slow reduction in global incidences, except in southeast Asia, the number of TB cases caused by resistant Mycobacterium tuberculosis, estimated at 259,000 cases in 2009, became a threat to TB control programs (WHO 2010). Unfortunately, most of the available drug susceptibility testing (DST) methods are either very time-consuming or too expensive to be widely adopted in low and middle-income countries. The proportion method (PM) (Canetti et al. 1963), the most commonly used method for determining susceptibility to drugs, requires up to two months for the results to be obtained. In the last decade, fast, reproducible and low-cost phenotypic methods for determining the susceptibility to drugs have been described, such as the Microscopic Observation Broth-Drug Susceptibility assay (Caviedes et al. 2002, Mello et al. 2007), the colourimetric redox-indicator (Reis et al. 2004, Martin et al. 2005, Silva et al. 2006, Sanchotene et al. 2008) and the nitrate reductase assay (NRA) (Angeby et al. 2002, Lemus et al. 2006, Palomino et al. 2008, Shikama et al. 2009). Among the low-cost techniques, the NRA appears to be feasible as a rapid, specific, sensitive and easily implemented DST method, especially for low and middleincome countries. The technique relies on the ability of metabolically active $M$. tuberculosis to reduce nitrate to

Financial support: NIH (Innovative Approaches for TB Control in Brazil) (ICOHRTA, U2R TW006885), FAPERJ, CNPq

+ Corresponding author: 1sfonseca@micro.ufrj.br

Received 11 April 2011

Accepted 9 August 2011 nitrite. The presence of nitrite is used as a growth indicator that can be visually detected by a colour change after adding chemical reagents that are usually available in any TB laboratory for the routine identification of $M$. tuberculosis isolates.

The purpose of this study was to evaluate the NRA for the rapid detection of resistance to isoniazid (INH), streptomycin (SM), ethambutol (EMB) and rifampicin (RMP) and to compare the NRA with PM on solid medium and the automatic commercial system BACTEC MGIT960 under routine conditions.

One hundred and six M. tuberculosis clinical isolates obtained from patients of the University Hospital Clementino Fraga Filho, Institute of Chest Diseases of Federal University of Rio de Janeiro (UFRJ) from June 2003December 2005 and the reference strain H37Rv (ATCC 27294), used as a control, were tested. All of the isolates and the control strain were maintained in Middlebrook $7 \mathrm{H} 9$ culture medium at $-20^{\circ} \mathrm{C}$ until they were tested. The antibiotics were obtained in pure powder form from Sigma Chemical Co (St Louis, MO, USA). The antibiotic stock solutions were prepared at $10 \mathrm{mg} / \mathrm{mL}$ by dissolving SM, INH and EMB in sterile distilled water and RMP in methanol. The stock solutions were stored at $-20^{\circ} \mathrm{C}$ until used.

The PM was performed as previously described. The test was conducted on Lowenstein-Jensen (LJ) medium at the recommended critical concentrations of $4.0 \mu \mathrm{g} /$ $\mathrm{mL}$ for SM, $0.2 \mu \mathrm{g} / \mathrm{mL}$ for INH, $40.0 \mu \mathrm{g} / \mathrm{mL}$ for RMP and $2.0 \mu \mathrm{g} / \mathrm{mL}$ for EMB.

For the DST using the M960 system, the drugs from the BACTEC MGIT960 SIRE kit were used following the standard procedure (Siddiqi \& Rüsch-Gerdes 2006). The final drug concentrations were $1.0 \mu \mathrm{g} / \mathrm{mL}$ for SM, $0.1 \mu \mathrm{g} / \mathrm{mL}$ for INH, $1.0 \mu \mathrm{g} / \mathrm{mL}$ for RMP and $5.0 \mu \mathrm{g} / \mathrm{mL}$ for EMB.

The NRA was performed as described by Angeby et al. (2002). Briefly, the antibiotic was included in the LJ medium at the recommended critical concentration for 
the PM; $1 \mathrm{mg} / \mathrm{mL}$ of potassium nitrate $\left(\mathrm{KNO}^{3}\right)$ was also added. A part of the inoculum, adjusted to have turbidity equal to the turbidity of a tube of $1 \mathrm{McF}$ arland standard, was diluted 1:10 in distilled water. For each isolate, $0.2 \mathrm{~mL}$ of the undiluted inoculum was added into the tubes containing the $\mathrm{LJ}^{\mathrm{J}}$ medium with $\mathrm{KNO}^{3}$ and the anti-TB drugs and $0.2 \mathrm{~mL}$ of the $1: 10$ dilution was inoculated into each of three tubes of drug-free media containing $\mathrm{KNO}^{3}$, serving as a triplicated growth control. The tubes were incubated at $37^{\circ} \mathrm{C}$ for 14 days and $0.5 \mathrm{~mL}$ of a mixture of three reagents - the nitrate reductase developer (1 part 50\% concentrated hydrochloric acid, 2 parts $0.2 \%$ sulfanilamide and 2 parts $0.1 \% \mathrm{~N}-1$-naphthylenthylenediamine dihydrochloride) - was added to one drug-free control tube after seven days of incubation. If a colour change was observed in the control, the developer was also added to the remaining tubes. If there was no colour change in the control tube, the tubes were returned to the incubator and the procedure was repeated on the 10th day and, if necessary, on the 14th day. A strain was considered resistant if any colour change was observed in the drug-containing tube. The ethical clearance of this study was granted by the University Hospital Clementino Fraga Filho.

The contribution of TB laboratories to the global management of multidrug-resistant (MDR) TB is important for the rapid determination of drug susceptibil- ity. Numerous alternative methods have been proposed for the detection of TB drug resistance. In this paper, the NRA was used as an alternative indirect method for the rapid detection of resistance to first-line antituberculous drugs in $106 \mathrm{M}$. tuberculosis clinical isolates with a high percentage of resistant strains (32 resistant to SM, 56 resistant to INH, 39 resistant to RMP and 21 resistant to EMB, with only 44 fully-sensitive isolates). An overall agreement of $95 \%$ was found between the NRA and PM methods (395 of 416 tests). The overall agreement between the NRA and M960 was 94\% (361 of 382 tests) (Table I). The sensitivity, defined as the ability to detect true resistance, specificity, defined as the ability to detect true susceptibility, and the accuracy are shown in Table II. The accuracy of the NRA for both of the standard methods, PM and M960, for RMP (99\% and 100\%, respectively) was very good according to the criteria established by the World Health Organisation/International Union Against Tuberculosis and Lung Disease/Supranational Laboratory Network, which has proposed accuracy levels of $>99 \%$ for RMP (Laszlo et al. 2002). For the other drugs, only the test with EMB achieved the recommended accuracy of $>92 \%$. For INH, five false-negative results were obtained with the NRA compared to the PM and six false-negative results compared to the MGIT. The accuracies obtained of $94.3 \%$ and $93.7 \%$ comparing the NRA

TABLE I

Agreement of the nitrate reduction assay (NRA) susceptibility with the reference methods

\begin{tabular}{|c|c|c|c|c|}
\hline & \multicolumn{2}{|c|}{ NRA $x$ proportion } & \multicolumn{2}{|c|}{ NRA x BACTEC MGIT960 } \\
\hline & $\begin{array}{l}\text { Concordant } \\
\text { strains/total } \\
\text { (n) }\end{array}$ & $\begin{array}{c}\text { Agreement } \\
(\%)\end{array}$ & $\begin{array}{l}\text { Concordant } \\
\text { strains/total } \\
\text { (n) }\end{array}$ & $\begin{array}{c}\text { Agreement } \\
(\%)\end{array}$ \\
\hline Streptomycin & $90 / 100$ & 90 & $87 / 96$ & 90.1 \\
\hline Isoniazid & $100 / 106$ & 94.3 & $90 / 96$ & 93.7 \\
\hline Rifampicin & $105 / 106$ & 99 & $96 / 96$ & 100 \\
\hline Ethambutol & $100 / 104$ & 96.1 & $88 / 96$ & 91.7 \\
\hline Total & $395 / 416$ & 94.9 & $361 / 384$ & 94 \\
\hline
\end{tabular}

TABLE II

Susceptibility and sensitivity results of the nitrate reduction assay (NRA) compared to those of the reference methods

\begin{tabular}{lcccc}
\hline & \multicolumn{2}{c}{ NRA x Lowenstein-Jensen } & \multicolumn{2}{c}{ NRA x BACTEC MGIT960 } \\
\cline { 2 - 3 } \cline { 4 - 5 } & $\begin{array}{c}\text { Sensitivity } \\
(\%)\end{array}$ & $\begin{array}{c}\text { Specificity } \\
(\%)\end{array}$ & $\begin{array}{c}\text { Sensitivity } \\
(\%)\end{array}$ & $\begin{array}{c}\text { Specificity } \\
(\%)\end{array}$ \\
\hline Streptomycin & 93.7 & 99 & 82 & 96.5 \\
Isoniazid & 91.1 & 100 & 88.6 & 100 \\
Rifampicin & 97.4 & 98.8 & 700 & 100 \\
Ethambutol & 85.7 & & 70.6 & 96.2 \\
\hline
\end{tabular}


with the PM and MGIT, respectively, did not match the accuracy of $>97 \%$ recommended for INH. According to Martin et al. (2008), who conducted the review and meta-analysis of the NRA, the sensitivity obtained in this study was slightly below the recommended level $(92 \%)$, but the specificity reached the specificity recommended by these authors (95\%) for comparisons of the NRA with the PM and MGIT standard DST tests (Table II). Also, the accuracy of the NRA test for SM was below the recommended level (92\%) (Martin et al. 2008) when the test was compared with the PM and MGIT, respectively $90 \%$ and $90.6 \%$, but SM is recognised as a difficult drug to test even using the standard methods (Lazlo et al. 2002). The accuracies obtained for INH of $94.3 \%$ and $93.7 \%$, below the recommended $97 \%$, surprised us. In a study of similar design, Shikama et al. (2009) obtained an agreement of up to $95 \%$ between the NRA and PM results, as well as between the NRA and M960. The false-sensitive results obtained in the present paper using the NRA may be due to borderline strains, with a low proportion of drug-resistant organisms in the test population, that although shown to be resistant by the PM and M960 tests, did not grow enough to reduce nitrate in the NRA method. The turnaround time of a test is important for the patient to receive an appropriate treatment. The results obtained with the NRA (8.8 days) are similar to those obtained with the M960 (7.3 days) and are available in a much shorter time than the 42 days required for the PM. Moreover, biosafety problems are limited because of the use of solid medium, reducing the risk of aerosol production during manipulation. The high agreement between the results of the NRA, PM and M960 for RMP is very important and indicates the potential of this simple and inexpensive assay for use in control programs in countries with high levels of TB endemicity. A resistance to RMP is almost always associated with MDR (Vareldzis et al. 1994) and can thus serve as a marker of MDR $M$. tuberculosis strains if resources are limited. The biggest advantage of the NRA is that it is performed in the classic LJ medium that TB laboratories use routinely for the diagnosis of TB, which makes this method easily implemented in routine laboratories. No expensive equipment is required to perform the NRA, facilitating its widespread application. A limitation of the NRA is that this method cannot be used for nitrate reductase-negative M. tuberculosis samples, but nitrate reductase-negative strains of M. tuberculosis are uncommon.

In conclusion, the NRA constitutes a useful tool for the detection of TB drug resistance in low-resource countries with limited laboratory facilities due to its low cost, ease of performance and lack of requirement for sophisticated equipment.

\section{REFERENCES}

Angeby KA, Klintz L, Hoffner SE 2002. Rapid and inexpensive drug susceptibility testing of Mycobacterium tuberculosis with a nitrate reductase assay. J Clin Microbiol 40: 553-555.

Canetti G, Froman S, Grosset J, Hauduroy P, Langerova M, Mahler HT, Meissner G, Mitchison DA, Sula L 1963. Mycobacteria: laboratory methods for testing drug sensitivity and resistance. Bull World Health Organ 29: 565-578.
Caviedes L, Lee TS, Gilman RH, Sheen P, Spellman E, Lee EH, Berg DE, Montenegro-James S, Tuberculosis Working Group in Peru 2002. Rapid, efficient detection and drug susceptibility testing of Mycobacterium tuberculosis in sputum by microscopic observation of broth cultures. J Clin Microbiol 38: 1203-1208.

Laszlo A, Rahman M, Espinal M, Raviglione M, WHO/IUATLD Network of Supranational Reference Laboratories 2002. Quality assurance programme for drug susceptibility testing of $\mathrm{Myco}-$ bacterium tuberculosis in the WHO/IUATLD Supranational Reference Laboratory Network: five rounds of proficiency testing, 1994-1998. Int J Tuberc Lung Dis 6: 748-756.

Lemus D, Montoro E, Echemendia M, Martin A, Portaels F, Palomino JP 2006. Nitrate reductase assay for detection of drug resistance in Mycobacterium tuberculosis: simple and inexpensive method for low-resource laboratories. J Med Microbiol 55: 861-863.

Martin A, Morcillo N, Lemus D, Montoro E, Telles MAS, Simboli N, Pontino M, Porras Y, León C, Velasco M, Chacon L, Barrera L, Ritacco V, Portaels F, Palomino JC 2005. Multicenter study of MTT and resazurin assays for testing susceptibility to first-line anti-tuberculosis drugs. Int J Tuberc Lung Dis 9: 901-906.

Martin A, Panaiotov S, Portaels F, Hoffner S, Palomino JC, Angeby $\mathrm{K}$ 2008. The nitrate reductase assay for the rapid detection of isoniazid and rifampicin resistance in Mycobacterium tuberculosis: a systematic review and meta-analysis $J$ Antimicrob Chemother 624: 56-64.

Mello FC, Arias MS, Rosales S, Marsico AG, Pavón A, AlvaradoGálvez C, Pessôa CLC, Pérez M, Andrade MK, Kritski AL, Fonseca LS, Chaissom RE, Kimerling ME, Dorman SE 2007. Clinical evaluation of the microscopic observation drug susceptibility assay for detection of Mycobacterium tuberculosis resistance to isoniazid or rifampin. J Clin Microbiol 45: 3387-3389.

Palomino JC, Martin A, Von Groll A, Portaels F 2008. Rapid culture based methods for drug-resistance detection in Mycobacterium tuberculosis. J Microbiol Methods 75: 161-166.

Reis RS, Neves Jr I, Lourenço SL, Fonseca S, Lourenço MCS 2004. Comparison of flow cytometric and alamarBlue tests with the proportional method for testing susceptibility of Mycobacterium tuberculosis to rifampin and isoniazid. J Clin Microbiol 42: 2247-2248.

Sanchotene KO, von Groll A, Ramos D, Scholante AB, Honscha G, Valença M, Scaini CJ, Silva PEA 2008. Comparative evaluation of the nitrate reductase assay and the resazurin microtitre assay for drug susceptibility testing of Mycobacterium tuberculosis against first line anti-tuberculosis drugs. Braz J Microbiol 39: 16-20.

Shikama ML, Silva RRF, Martins MC, Giampaglia CMS, Oliveira RS, Silva RFAM, Silva PF, Telles MAS, Martin A, Palomini JC 2009. Rapid detection of resistant tuberculosis by nitrate reductase assay performed in three settings in Brazil. J Antimicrob Chemother 64: 794-796.

Siddiqi SH, Rüsch-Gerdes S 2006. MGIT Procedure Manual. Available from: finddiagnostics.org/export/sites/default/resourcecentre/find_documentation/pdfs/mgit_manual_nov_2007.pdf.

Silva PA, Boffo M, Mattos I, Silva AB, Palomino JC, Martin A, Takiff H 2006. Comparison of redox and D29 phage methods for detection of isoniazid and rifampicin resistance in Mycobacterium tuberculosis. Clin Microbiol Infect 12: 293-296.

Vareldzis BP, Grosset J, Kantor I, Crofton J, Laszlo A, Felten M, Raviglione MC, Kochi A 1994. Drug-resistant tuberculosis: laboratory issues. World Health Organization recommendations. Tuber Lung Dis 75: 1-7.

WHO - World Health Organization 2010. Global tuberculosis control. WHO report 2010, WHO, Geneva, 218 pp. 